\title{
Erken müdahale ve erken çocuklukta Özel Eğitim Alanında Tavsiye Edilen Uygulamalara (TEdU) ilişkin Türk paydaşların bakış açılarının incelenmesi
}

\author{
An investigation of key Turkish stakeholders' perspectives about \\ Recommended Practices in early intervention and early childhood special \\ education
}

\begin{abstract}
Makale Geçmişi
Geliş : 31 Mayıs 2020

Düzeltme : 5 Ağustos 2020

Kabul : 12 Eylül 2020
\end{abstract}

\section{Makale Türü}

Araştırma Makalesi

\section{Article History}

Received : 31 May 2020

Revised : 5 August 2020

Accepted : 12 September 2020

\section{Article Type}

Research Article

\author{
Salih Rakap ${ }^{1}$, Sinan Kalkan², Şerife Balıkc1
}

\begin{abstract}
Öz: Bu çalısmanın amacı, Türkiye'deki kilit paydaşların (öğretmenler, ebeveynler, yöneticiler ve yükseköğretim öğretim elemanları) Amerika Birleşik Devletleri'nde Özel Gereksinimli Çocuklar Konseyi Erken Çocukluk Birimi tarafindan geliştirilen Tavsiye Edilen Uygulamalar (TEdU) hakkındaki görüşlerini incelemektir. Bu çalışmada, nicel araştırma tekniklerinden betimsel tarama yöntemi kullanılmıştır. Çalışmaya, Türkiye'nin yedi şehrinden 122'i öğretmen, 100'ü ebeveyn, 40'ı yönetici ve 32'si ise yüksek öğrenim kurumlarından çalışan öğretim elemanları olmak üzere toplam 294 kişi katılmıştır. $\mathrm{Bu}$ çalışmada veriler araştırmacılar tarafından TEdU temel alınarak geliştirilen bir anket aracilığıyla toplanmıștır. Çalışmada gruplar arasındaki farklılıkları araștırmak için tek yönlü ANOVA analizleri yapılmış ve istatistiksel olarak anlamlı bir ana etki gözlenmemesi durumunda hangi gruplar arasında farklılık olduğunu belirlemek için Tukey post-hoc analizi uygulanmıştır. Bulgular, 65 uygulamanın hepsinin geçerlilik ölçütünü karşıladığını göstermiş olup tüm TEdU’ların Türkiye'deki paydaşlar tarafından önemli olarak algılandığını ortaya koymuştur. Bu çalışmanın bulguları, öğretmenlerin ve özel gereksinimli küçük çocuklara hizmet sağlayan diğer uzmanların uygulamalarında TEdU'ları kullanmasını kolaylaştırmak için sistem düzeyinde destek ve altyapı geliştirme ihtiyacını ortaya koymaktadır.
\end{abstract}

Anahtar Kelimeler: Tavsiye edilen uygulama, Erken müdahale, Erken çocuklukta özel eğitim

Abstract: Recommended Practices (RPs) are developed to bridge the gap between research and practice and offer guidance to parents and practitioners who work with young children (birth through five years of age) who have or are at risk for developmental delays or disabilities. The purpose of this study was to investigate perspectives of key stakeholders in Turkey about the new RPs using a descriptive survey design. A total of 294 stakeholders including teachers, parents, administrators and higher education personal participated in the study. Findings showed that all 65 practices met the validation criterion, meaning that all RPs were perceived as important by stakeholders in Turkey. In contrast to these promising findings, results with respect to reported use of the RPs in early childhood settings showed that these practices were rarely or never used by practitioners. Recommendations for future practice and research are provided.

Keywords: Recommended practices, Early intervention, Early childhood special education

${ }^{1}$ Ondokuz Mayıs Üniversitesi, Eğitim Fakültesi, Özel Eğitim Bölümü, srakaptr@gmail.com, ORCID: https://orcid.org/0000-0001-7853-3825

${ }^{2}$ Çanakkale Onsekiz Mart Üniversitesi, Eğitim Fakültesi, Özel Eğitim Bölümü, snnklkn35@gmail.com, ORCID: https://orcid.org/0000-00016890-6421

${ }^{3}$ Milli Eğitim Bakanlığı, Çarşamba Dumlupınar İlkokulu, seriferakap@gmail.com, ORCID: https:/ orcid.org/0000-0003-3740-8037 


\section{SUMMARY}

\section{Introduction}

Initially developed between 1991-1993 to provide guidance to relatively new early intervention/early childhood special education field (EI/ECSE; McLean, Swett, \& Trivette, 2014; Odom, McLean, Johnson, \& LaMontagen, 1995; Rapport, McWilliam, Smith, 2004), Division for Early Childhood Recommended Practices (DEC RP) have been among the major efforts aiming to bridge the gap between research and practice in EI/ECSE by identifying practices that have been found to result in improved outcomes for young children with delays and disabilities, their families, and professionals who work with them (DEC, 2014; Odom \& McLean, 1996). Since the initial set of practices published in 1993 (i.e., 415 practices under 14 strands), the DEC RPs have been updated and revised several times and the latest version of the Recommended Practices is published in 2014. The effort to update and revise DEC RPs resulted in 66 practices under 8 topic areas including Leadership, Assessment, Environment, Family, Instruction, Interaction, Teaming and Collaboration, and Transition.

The purpose of this study was to investigate opinions of key stakeholders (i.e., teachers, parents, administrators, and higher education personal) in Turkey about the new set of PRs developed in the United States. This study will provide useful information for the relatively new field of EI/ECSE in Turkey as services for young children who have or at-risk for developmental delays and disabilities are currently being developed. In addition, the present study will be the first study to evaluate the RPs in an international context.

\section{Method}

A descriptive survey design was used in the present study. Study sample included four groups of stakeholders: teachers and parents of children with disabilities, school administrators, and higher education personal. A total of 294 stakeholders across four groups participated in the study. A questionnaire was developed using the RPs and distributed to potential participants. Participants were given the survey package including a consent form, the questionnaire, a demographic information form, and an instruction letter explaining how to complete and return the survey package if willing to participate in the study. Respondents were given two weeks to complete the survey package and return it to the researchers.

For each RP on the questionnaire, frequency and percentage of response categories selected by participants were calculated. Mean ratings were calculated for each stakeholder group by eight topic areas to determine whether differences in ratings existed across groups. One-way ANOVA analyses were conducted to investigate differences across groups and Tukey post-hoc analyses were computed to determine the exact location differences when a statistically significant main effect was observed. 


\section{Results}

As in McLean et al. (2002), a practice was considered a recommended practice when more than $50 \%$ of participants selected agree or strongly agree option for an item as a response to "Should this be a recommended practice?" question. All 65 practices included in the questionnaire met this criterion. Moreover, for every practice, $83 \%$ or more of the participants selected either agree or strongly agree. Among the 8 topic areas, practices associated with Instruction had the highest endorsement from participants while practice associated with Leadership had the lowest endorsement.

With respect to current use of RPs in the field, ratings of frequently ranged between 1\% (Leadership, Environment, Family, Teaming and Collaboration, and Transition) and 8\% (Instruction). Ratings of sometimes ranged between 6\% (Transitions) and 21\% (Assessment). Ratings of rarely ranged between 31\% (Transition) and 55\% (Interaction). Ratings of never ranged between 19\% (Interaction) and 53\% (Transition). Missing data ranged between 1\% (Assessment and Instruction) and 12\% (Leadership).

\section{Discussion}

Findings showed that all 65 practices met the validation criterion (i.e., more than $50 \%$ of participants selecting agree or strongly agree option for a practice), meaning that all RPs were perceived as important by stakeholders in Turkey. In contrast to these promising findings, results with respect to reported use the RPs in early childhood settings showed that RPs were rarely or never used by early childhood practitioners.

Comparison among the stakeholder groups revealed that although statistically significant group differences were observed in only three topic areas (Leadership, Environment, and Family) for the first research question (i.e., Should this be a RP?), higher education professionals or administrators had a higher mean score in all topic areas than teachers and parents. This finding is consistent with the findings of McLean et al. (2002) who also reported higher mean scores for higher education professionals or administrators in all strands when compared to other stakeholder groups. Mean scores of stakeholder groups significantly differed in two topic areas for the second question (i.e., To what extent do you see this RP in practice?): Assessment and Family.

Overall, findings of the present study suggested that although majority of stakeholders agree that the RPs should be recommended practices for EI/ECSE field in Turkey, teachers use these practices infrequently while working with young children with disabilities and their families. These two findings together suggest the need for developing systems level support and infrastructure to facilitate teachers and other EI/ECSE service providers' use RPs in their practice. 


\section{GİRIŞ}

İlk olarak, 1991-1993 yılları arasında, nispeten yeni olan Erken Müdahale (EM)/Erken Çocuklukta Özel Eğitim (EÇÖzE) alanına rehberlik etmesi amacıyla Özel Gereksinimli Çocuklar Konseyi (CEC) Erken Çocukluk Birimi (DEC; Division for Early Childhood) tarafından geliştirilen Tavsiye Edilen Uygulamalar (TEdU; Recommended Practices McLean, Swett ve Trivette, 2014; Odom, McLean, Johnson ve LaMontagen, 1995; Rapport, McWilliam, Smith, 2004), gelişimsel gerilik gösteren ve yetersizlikten etkilenmiş çocuklar, aileleri ve onlarla çalışan uzmanlara yol gösteren temel kaynaklardan biri haline gelmiştir. Erken Çocukluk Birimi, özel gereksinimli çocuklar ve aileleri için yararlı olduğu ve olumlu sonuçlara yol açtı̆̆ı tespit edilen uygulamaları belirleyerek ve bu uygulamaların kullanımının yaygınlaştırılmasını destekleyerek EM/EÇÖzE'de araştırma ve uygulama arasındaki boşluğu kapatmayı amaçlamaktadır (DEC, 2014; Odom ve McLean, 1996).

TEdU'lar, 14 ana başlık altında 415 uygulama olarak ilk yayınlandıkları 1993 yılından bu yana birkaç kez güncellenmiş ve revize edilmiştir. Bu bağlamda, ilk büyük revizyon, daha titiz ve sistematik bir süreç kullanılarak TEdU'ları güncellemek amacıyla 1998 yılında gerçekleştirilmiştir (Rapport vd., 2004). Özel Eğitim Programları Ofisi'nden (OSEP; Office of Special Education Programs) sağlanan federal hibe desteği ile Erken Çocukluk Birimi Tavsiye Edilen Uygulamalar ekibi alanyazının gözden geçirilmesi için titiz bir süreç geliştirmiş ve alanyazındaki veri tabanlarını kapsamlı bir şekilde incelemiştir (McLean vd., 2014; Rapport vd., 2004). İnceleme süreci boyunca, 48 dergide 1000 'den fazla makale, tanımlanan kodlama kriterleri ve eğitimli kodlayıcılar kullanılarak gözden geçirilmiş ve kodlanmıştır. Ayrıca araştırmacılar, uygulayıcılar, aileler ve yöneticiler de dahil olmak üzere farklı paydaşlarla odak grup görüşmeleri yapılmıştır. Alanyazın incelemeleri ve odak grup görüşmeleri yoluyla toplanan bilgiler daha sonra yeni Tavsiye Edilen Uygulamalar listesini oluşturmak için sentezlenmiş, senkronize edilmiş ve bu yeni uygulamalar, uygulayıcılar, aileler, yöneticiler, yükseköğretim öğretim elemanları da dahil olmak üzere 388 paydaş tarafından değerlendirilmiştir (McLean vd., 2014; McLean, Snyder, Smith ve Sandall, 2002). Erken Çocukluk Birimi tarafindan yürütülen bu çabalar yedi ana başlık (Değerlendirme, Çocuk-Odaklı Müdahaleler, Aile-Temelli Uygulamalar, Disiplinlerarası Modeller, Teknoloji, Politika ve Sistem Değissimi, Personel Hazırlama) alında 240 Tavsiye Edilen Uygulama ile sonuçlanmıştır (DEC, 2000; 2005). Tavsiye edilen 240 uygulamadan 154'ü (\%64) deneysel çalışma, mesleki bilgi ve fikir birliğine, 86's1 (\%36) ise mesleki bilgi ve fikir birliğine dayalı olarak geliştirilmiştir (McLean vd., 2014).

Tavsiye Edilen Uygulamaları güncellemek amacıyla yürütülen ikinci büyük çaba 2011-2014 yılları arasında gerçekleşmiştir. Erken Çocukluk Birimi Yönetim Kurulu 2011 yllında, TEdU'ların revize edilmesine olan ihtiyacı tespit etmek ve revize edilecekse hangi yöntemlerin kullanılması gerektiğini 
belirlemek amacıyla bir çalışma grubu oluşturmuştur. Çalışma grubunun çalışmaları ve sahadan gelen anketler yoluyla elde edilen verilere dayanarak, Erken Çocukluk Birimi Yönetim Kurulu, Erken Çocukluk Teknik Yardım Merkezi (Early Childhood Technical Assistance) ile işbirliği yaparak ve Özel Eğitim Programları Ofisi'nin desteği ile TEdU'ları güncellemeye karar vermiştir. Bu amaçla, Erken Çocukluk Birimi Tavsiye Edilen Uygulamalar Komisyonu 2013 yılının ilk yarısında Liderlik, Değerlendirme, Çevre, Aile, Öğretim, Etkileşim, Ekip ve İşbirliği ve Geçiş dahil olmak üzere sekiz ana başlık altında uygulamaları gözden geçirmek ve güncellemek için ayrı çalışma grupları oluşturmuştur (McLean vd., 2014). Erken Çocukluk Birimi’nin TEdU'ları güncelleme ve gözden geçirme çabası sekiz ana başlık altında 66 uygulama ile sonuçlanmıştır. Bu yeni TEdU'lar belirli bir yetersizliğe özgü olmayıp alandaki bilgi, deneyim ve araştırmalar temel alınarak gözlemlenebilir nitelikte geliştirilmiştir. TEdU’lar oldukça kapsamlı ve ana başlıkta belirtilen konuyu temsil edecek derinliktedir. TEdU'lar, tipik gelişim gösteren çocukların devam ettikleri erken çocukluk ortamları için geliştirilen uygulamalar veya standartlar temel alınarak geliştirilmiş, doğal ve kapsayıcı ortamlar da dahil olmak üzere tüm erken çocukluk ortamlarında uygulanabilir niteliktedir (DEC, 2014). Her bir ana başlık altında yer alan tavsiye edilen uygulamalara birer örnek Şekil 1'de sunulmuştur.

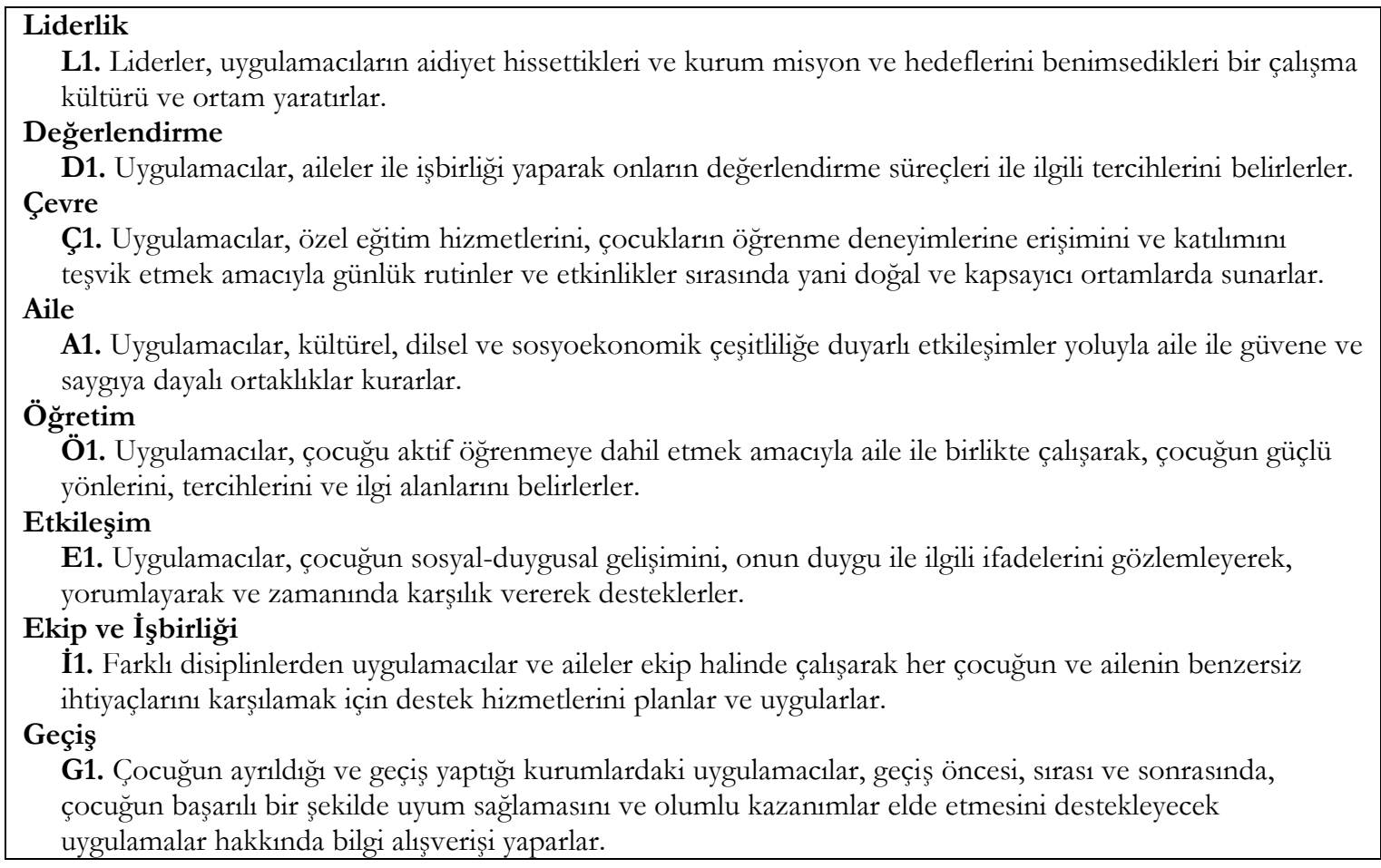

Şekil 1. Tavsiye Edilen Uygulama Ömekleri

Bu çalışmanın amacı, Türkiye'deki kilit paydaşların (öğretmenler, ebeveynler, yöneticiler ve yükseköğretim öğretim elemanları) Amerika Birleşik Devletleri'nde Erken Çocukluk Birimi 
tarafından geliştirilen yeni Tavsiye Edilen Uygulamalar hakkındaki görüşlerini incelemektir. Yetersizlikten etkilenmiş küçük çocuklara ve ailelerine EM/EÇÖzE hizmetleri sunmanın önemi 1980'li yıllardan beri Türk hükümetleri ve mevzuatları tarafından kabul edilmiş olmasına rağmen, 2000 yllında yayımlanan Özel Eğitim Hizmetleri Yönetmeliği, doğrudan EM/EÇÖzE hizmetleri için rehber niteliğinde olan ilk yasal belgedir (Diken vd., 2016). Bu yasal düzenlemelere rağmen Türkiye'de özellikle 0-3 yaş grubundakiler olmak üzere erken çocukluk dönemindeki özel gereksinimli çocuklara ve ailelerine sunulan hizmetler oldukça sınırlı düzeydedir (Rakap, 2017). Dahası, ülkemizde EM/EÇÖzE hizmetleri bağlamında kullanılabilecek etkili uygulamaların belirlenmesine ve kullanımının özendirilmesine yönelik kapsamlı bir çalışma bulunmamaktadır. Bu kültürler arası geçerlilik çalışması, Türkiye'de yeni gelişmekte/yaygınlaşmakta olan EM/EÇÖzE alanı için oldukça kullanışlı ve yararlı bilgiler sunacaktır (Rakap ve Rakap, 2015). Buna ek olarak bu çalışma, Tavsiye Edilen Uygulamaların geçerliliğinin uluslararası bağlamda değerlendirildiği ilk çalışma olması nedeniyle Erken Çocukluk Teknik Yardım Merkezi ile işbirliği içinde Tavsiye Edilen Uygulamaların uygulanmasını ve yaygın kullanımını artırmayı amaçlayan Erken Çocukluk Birimi için de değerli bilgiler sağlayacaktır.

Bu çalışma, 1998 yllında gözden geçirilen ve 2000 y1lında yayınlanan Erken Çocukluk Birimi TEdU'larını değerlendirmek amacıyla McLean vd. (2002) tarafından yürütülen sosyal geçerlik çalışmasının sistematik bir tekrarıdır. Bu çalışmada iki araştırma sorusu ele alınmıştır: (a) Türkiye'deki kilit EM/EÇÖzE paydaşlarının (öğretmenler, ebeveynler, yöneticiler ve yükseköğretim meslek elemanları), Erken Çocukluk Birimi tarafindan belirlenen uygulamaların Türkiye'deki EM/EÇÖzE alanı için tavsiye edilen uygulama olarak kabul edilmesi konusundaki görüşleri nelerdir? (b) Türkiye'deki kilit EM/EÇÖzE paydaşları, Erken Çocukluk Birimi tarafindan belirlenen uygulamaların bildikleri/çalıştıkları programlarda ne ölçüde kullanıldığını rapor etmektedirler?

\section{YÖNTEM}

\section{Araştırma Modeli}

Türkiye'deki kilit paydaşların (öğretmenler, ebeveynler, yöneticiler ve yükseköğretim meslek elemanları) Amerika Birleşik Devletleri'nde Erken Çocukluk Birimi tarafından geliştirilen yeni Tavsiye Edilen Uygulamalar hakkındaki görüşlerini incelemeyi amaçlayan bu çalışmada, nicel araştırma tekniklerinden betimsel tarama yöntemi kullanılmıştır (Büyüköztürk vd., 2019). 


\section{Katılımcilar}

$\mathrm{Bu}$ çalışmaya, yetersizlikten etkilenmiş çocukların öğretmenleri, ebeveynleri, yükseköğretim kurumlarının özel eğitim öğretmenliği, okulöncesi öğretmenliği ve çocuk gelişimi programlarında görev yapan öğretim elemanları ile özel eğitim ve okulöncesi eğitim kurumu yöneticileri olmak üzere dört paydaş grubu dahil edilmiştir. Çalışma, Türkiye'deki yedi şehirde 500 öğretmen, 250 ebeveyn ile 250 yönetici ve öğretim elemanına toplam 1000 anket formu dağıtarak gerçekleştirilmiştir. Toplam 301 (\%30) katılımcı belirtilen süre içerisinde anketi tamamlayarak araştırmacılara geri göndermişlerdir. Araştırmacılara teslim edilen 301 anketin yedisi eksik cevaplar olması nedeniyle örneklemden çıkarılmış ve veri analizleri toplam 294 anket kullanılarak gerçekleştirilmiştir. Çalışmaya katılan 294 kişinin 122'i öğretmen, 100'ü ebeveyn, 40’1 yönetici ve 32'si ise öğretim elemanıdır. Çalışmaya dahil olan 294 katılımcıdan 202'si kadın, 92'si ise erkektir. Katılımcıların yetersizlikten etkilenmiş küçük çocuklarla çalışma deneyimleri 1 ile 32 yıl arasında değişmekte olup ortalama 11,5 yıl olarak belirlenmiştir. Katılımcılara ilişkin ilgiler Tablo 1'de sunulmuştur.

Tablo 1. Katılımcıların Karakteristik Özellikleri

\begin{tabular}{lcccc}
\hline Özellik & $\begin{array}{c}\text { Ö̆gretmen } \\
(\mathrm{n}=122)\end{array}$ & $\begin{array}{c}\text { Ebeveyn } \\
(\mathrm{n}=100)\end{array}$ & $\begin{array}{c}\text { Yönetici } \\
(\mathrm{n}=40)\end{array}$ & $\begin{array}{c}\text { Öğretim Elemanı } \\
(\mathrm{n}=32)\end{array}$ \\
\hline Cinsiyet (Kadın/Erkek) & $70 / 52$ & $95 / 5$ & $25 / 15$ & $12 / 20$ \\
\hline Yaş (yıl; ortalama/ranj) & $38,5(22-49)$ & $34,6(24-41)$ & $42,7(36-52)$ & $44,2(31-54)$ \\
\hline Deneyim (yıl; ortalama/ranj) & $13,5(1-22)$ & $8,7(3-21)$ & $11,7(6-19)$ & $12,5(4-32)$ \\
\hline
\end{tabular}

\section{Veri Toplama Arac1/Süreci}

Bu çalışmada veri toplama aracı olarak 65 TEdU (14 uygulamadan oluşan Liderlkk konu alanında yer alan 11. uygulama Türk eğitim sistemi bağlamında uygun olmadığ1 için kullanılmamıştır; dolayısıyla ankette 66 madde yerine 65 madde yer almaktadır) temel alınarak geliştirilen bir anket kullanılmıştır. Ankette, TEdU’ların İngilizce versiyonlarına ek olarak katılımcılara kolaylık olması amacıyla üç aşamalı bir süreç takip edilerek geliştirilmiş Türkçe versiyonlarına da yer verilmiştir. $\mathrm{Bu}$ bağlamda, ilk olarak, İngilizce ve Türkçe dillerine hâkim, ABD ve Türkiye'deki EM/EÇÖzE hakkında bilgili iki kişi bağımsız olarak tüm TEdU'ları Türkçeye çevirmiş ve bu çeviriler karşılaştırılmıştır. Çevirilerde olan farklılıklar ve anlaşmazlıklar arabuluculuk ve tartışma yoluyla giderilmiştir. İkincisi, yukarıda belirtilen niteliklere sahip olan diğer bir uzman bağımsız olarak tüm TEdU'ları tekrar İngilizceye çevirmiş ve bu çeviri ile TEdU'ların orijinal versiyonu karşılaştırılmıştır. Çeviri ve orijinal versiyonlar arasındaki tutarsızlıklar belirlenerek Türkçe versiyonunda ek değişiklikler yapılmıştır. Daha sonra, bu çalışmaya katılan paydaşları temsil eden 20 kişiye (dört 
paydaş grubunun her birinden 5'er kişi) 65 soruluk anket uygulanmıştır. Bu aşamada, katılımcılardan ankette yer alan maddelerin netliği ve anlaşllabilirliği hakkında bilgi toplamak amaçlanmıştır. Bu bağlamda, katılımcılardan ankette yer alan her bir TEdU'yu okumaları, bir TEdU'nun açık ve anlaşılır olması durumunda "evet", belirsiz ve anlaşılması güç olması durumunda ise "hayır" seçeneklerini işaretlemeleri istenmiştir. Katılımcılardan "hayır" seçeneğini seçmeleri halinde, ek olarak, TEdU'ları daha anlaşıllır hale getirebilmek için görüşlerini kaydetmeleri talep edilmiştir. Bu aşamada elde edilen bilgiler, anketin revize edilmesi ve bu çalışmada kullanılan son halinin oluşturulması için kullanılmıştır. Son aşamadaki 20 katılımcının verileri bu çalışmadaki veri analizine dahil edilmemiştir. Ankete çalışmanın birinci yazarı ile iletişime geçilerek ulaşılabilir.

TEdU'ların son hali kullanılarak bir Sosyal Geçerlik Anketi tasarlanmıs ve katılımcılardan tavsiye edilen her bir uygulamayı iki soruya göre puanlandırmalar istenmiştir: (1) Bu uygulama, Türkiye'deki EM/EÇÖzE alanı için tavsiye edilen bir uygulama olmalı mıdır? ve (2) Bu uygulama, bildiğiniz/çalıştığınız programlar/kurumlar tarafindan ne ölçüde kullanılıyor? İlk soru için, (1) kesinlikle katılıyorum, (2) katıliyorum, (3) kesinlikle katılmıyorum, (4) katılmiyorum veya kararsızım derecelerine sahip 4'lü Likert tipi bir anket kullanılmıştır. Uygulamaların mevcut kullanımını değerlendirmek için ise (1) Asla, (2) Nadiren, (3) Bazen, (4) Stk veya Yanıt Yok derecelerinden oluşan 4'lü Likert tipi bir anket kullanılmıştır. Çalışma kapsamında her bir soru bağlamında toplanan veriler kullanılarak konu alanlarına ilişkin Cronbach Alfa İç Tutarlılık Katsayısı hesaplanmıştır. İlk soru kapsamında toplanan veriler bağlamında, konu alanlarına ilişkin iç tutarlılık katsayılarının .86 ile .94 arasında değiştiği belirlenmiştir. İkinci soru bağlamında ise iç tutarlılık katsayılarının .84 ile .93 arasında olduğu tespit edilmiştir.

Veri toplama sürecinde katılımcılara, bilgilendirilmiş/aydınlatılmış onam formu, anket, demografik bilgi formu ve çalışmaya katılmak isterlerse formların nasıl doldurulacağını ve teslim edileceğini açıklayan bir yönerge metni verilmiştir. Çalışmaya katılmak isteyen paydaşlara formları doldurmaları ve araştırmacılara posta yoluyla göndermeleri ya da elden teslim etmeleri için iki hafta süre verilmiştir. Çalışma kapsamında veri toplama işlemlerine geçilmeden önce birinci yazarın görev yaptığı kurumdaki Sosyal ve Beşerî Bilimler Araştırmaları Etik Kurulundan etik kurul izni alınmıştır.

\section{Veri Analizi}

Anketteki her bir TEdU için katılımcılar tarafindan seçilen cevap kategorilerinin sıklı̆̆ı ve yüzdesi hesaplanmıştır. Gruplar arasında puanlandırma farklılıklarının olup olmadığını belirlemek amacıyla her bir paydaş grubu için sekiz ana başlık bağlamında ortalama puan hesaplaması yapılmıştır. Gruplar arasındaki farklılıkları araştırmak için tek yönlü ANOVA analizleri yapılmış ve istatistiksel 
olarak anlamlı bir ana etki gözlenmemesi durumunda hangi gruplar arasında farklılık olduğunu belirlemek için Tukey post-hoc analizi uygulanmıştır.

\section{BULGULAR}

\section{Tavsiye Edilen Uygulamaların Geçerliliği}

McLean vd. (2002) yaptığı çalışmada olduğu gibi, bir uygulama, katılımcıların \%50'sinden fazlası "Bu uygulama, Türkiye'deki EM/EÇÖzE alanı için tavsiye edilen bir uygulama olmalı mıdır?" sorusunu "katılıyorum veya kesinlikle katılıyorum" şeklinde cevaplandırdıklarında tavsiye edilen uygulama olarak kabul edilmiştir. Ankete dahil edilen 65 uygulamanın tümü bu kriteri karşılamıştır. Ayrıca, her uygulama için katılımcıların \%83'ü veya daha fazlası "katılıyorum" ya da "kesinlikle katılıyorum" seçeneğini işaretlemiştir. Ankette yer alan sekiz ana konu alanı arasında Öğretim ile ilgili uygulamalar katılımcılardan en yüksek puanı (\%95 kesinlikle katılıyorum + katılıyorum) alırken, Liderlik ile ilişkili uygulamalar en düşük puanı (\%83 katılıyorum + katılıyorum) almıştır. Söz konusu

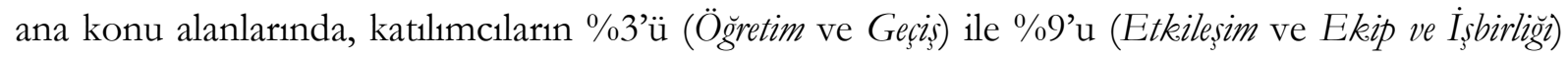
"katılmıorum" seçeneğini işaretlemiştir. Tüm konu alanlarında ise katılımcıların \%1'i "kesinlikle katılmıyorum" seçeneğini işaretlemişlerdir. Konu alanlarına göre ilk soruya verilen cevapların yüzde ve siklık düzeyleri Tablo 2'de gösterilmektedir.

Tablo 2. Soru 1 için Seçilen Yanıt Kategorilerinin Yüzdesi (Sıklığı): "Bu Uygulama, Türkiye'deki EM/EÇÖzE Alanı İçin Tavsiye Edilen Bir Uygulama Olmalı Mıdır?”

\begin{tabular}{|c|c|c|c|c|c|}
\hline Konu Alanı & $\begin{array}{l}\text { Kesinlikle } \\
\text { Kattliyorum }\end{array}$ & Katıliyorum & Katılmiyorum & $\begin{array}{l}\text { Kesinlikle } \\
\text { Katılmiyorum }\end{array}$ & Kararsızım \\
\hline $\begin{array}{l}\text { Liderlik } \\
\text { (13 uygulama*/3822 yanit) }\end{array}$ & $\begin{array}{c}29 \\
(1108)\end{array}$ & $\begin{array}{c}54 \\
(2064)\end{array}$ & $\begin{array}{c}4 \\
(153)\end{array}$ & $\begin{array}{c}1 \\
(38)\end{array}$ & $\begin{array}{c}12 \\
(459)\end{array}$ \\
\hline $\begin{array}{l}\text { Değerlendirme } \\
\text { (11 uygulama/3234 yanıt) }\end{array}$ & $\begin{array}{c}76 \\
(2458)\end{array}$ & $\begin{array}{c}17 \\
(550)\end{array}$ & $\begin{array}{c}5 \\
(162)\end{array}$ & $\begin{array}{c}1 \\
(32)\end{array}$ & $\begin{array}{c}1 \\
(32)\end{array}$ \\
\hline $\begin{array}{l}\text { Çevre } \\
\text { (6 uygulama/1764 yanıt) }\end{array}$ & $\begin{array}{c}52 \\
(917)\end{array}$ & $\begin{array}{c}37 \\
(653)\end{array}$ & $\begin{array}{c}6 \\
(105)\end{array}$ & $\begin{array}{c}1 \\
(18)\end{array}$ & $\begin{array}{c}4 \\
(71)\end{array}$ \\
\hline $\begin{array}{l}\text { Aile } \\
\text { (10 uygulama/2940 yanit) }\end{array}$ & $\begin{array}{c}44 \\
(1294)\end{array}$ & $\begin{array}{c}41 \\
(1205)\end{array}$ & $\begin{array}{c}8 \\
(235)\end{array}$ & $\begin{array}{c}1 \\
(29)\end{array}$ & $\begin{array}{c}6 \\
(177)\end{array}$ \\
\hline $\begin{array}{l}\text { Öğretim } \\
\text { (13 uygulama/3822 yanıt) }\end{array}$ & $\begin{array}{c}81 \\
(3096)\end{array}$ & $\begin{array}{c}14 \\
(535)\end{array}$ & $\begin{array}{c}3 \\
(115)\end{array}$ & $\begin{array}{c}1 \\
(38)\end{array}$ & $\begin{array}{c}1 \\
(38)\end{array}$ \\
\hline $\begin{array}{l}\text { Etkileşim } \\
\text { (5 uygulama/1470 yanıt) }\end{array}$ & $\begin{array}{c}34 \\
(500)\end{array}$ & $\begin{array}{c}51 \\
(750)\end{array}$ & $\begin{array}{c}9 \\
(132)\end{array}$ & $\begin{array}{c}1 \\
(15)\end{array}$ & $\begin{array}{c}5 \\
(73)\end{array}$ \\
\hline $\begin{array}{l}\text { Ekip ve İşbirliği } \\
\text { (5 uygulama/1470 yanıt) }\end{array}$ & $\begin{array}{c}38 \\
(559) \\
\end{array}$ & $\begin{array}{c}48 \\
(706) \\
\end{array}$ & $\begin{array}{c}9 \\
(132) \\
\end{array}$ & $\begin{array}{c}1 \\
(15) \\
\end{array}$ & $\begin{array}{c}4 \\
(58) \\
\end{array}$ \\
\hline $\begin{array}{l}\text { Geçiş } \\
\text { (2 uygulama/588 yanıt) }\end{array}$ & $\begin{array}{c}41 \\
(241) \\
\end{array}$ & $\begin{array}{c}46 \\
(270) \\
\end{array}$ & $\begin{array}{c}3 \\
(18) \\
\end{array}$ & $\begin{array}{c}1 \\
(6) \\
\end{array}$ & $\begin{array}{c}9 \\
(53) \\
\end{array}$ \\
\hline \multicolumn{6}{|c|}{$\begin{array}{l}\text { Not. EM = Erken Müdahale; EÇÖzE = Erken Çocuklukta Özel Ĕ̆itim. } \\
\text { * Liderlik konu alanında } 14 \text { uygulama bulunmaktadır; ancak bu konu alanı altında yer alan 11. uygulama Türk eğitim } \\
\text { sistemi bağlamında uygulanabilir olmadığı için ankete dahil edilmemiştir (Uygulama 11: Liderler, DEC, CEC ve diğger } \\
\text { ulusal mesleki standartlarla uyumlu, eyalet mesleki yeterlilikleri geliştirmek veya revize etmek için yüksek öğrenim } \\
\text { kurumları, eyalet lisanslama ve sertifika kuruluşları, uygulayıcılar, profesyonel dernekler ve diğer paydaşlarla işbirliği } \\
\text { yaparlar). }\end{array}$} \\
\hline
\end{tabular}




\section{Tavsiye Edilen Uygulamaların Mevcut Kullanımı}

Bu çalışma bağlamında ele alınan ikinci soru TEdU'ların Türkiye'deki EM/EÇÖzE sistemi bağlamında ne ölçüde kullanıldığı ile ilgilidir. Anketin ikinci sorusu olan "Bu uygulama, bildiğiniz/çalıştığınız programlar/kurumlar tarafindan ne ölçüde kullanıllyor?” sorusuna ilişkin katılımcıların verdiği cevaplar konu alanlarına göre Tablo 3'te sunulmuştur. Buna göre "sıklıkla" seçeneği katıllımcıların \%1'i (Liderlik, Çevre, Aile, Ekip ve Işsbirliği ve Geçiş) ile \%8’i (Öğretim) tarafından seçilirken, "bazen” seçeneği ise katılımcıların \%6’sı (Geçiş) ile \%21’i (Değerlendirme) tarafindan seçilmiştir. Maddelere "Nadiren” olarak verilen cevapların oranı \%31 (Geçiss) ile \%55 (Etkileşim) arasında; "Asla" olarak verilen cevaplanın oranı \%19 (Etkileşim) ile \%53 (Geçiss) arasında ve maddelere "Yanıt Yok" olarak verilen cevapların oranı ise \%1 (Dĕgerlendirme ve Öğretim) ile \%12 (Liderlik) arasında değişmektedir.

Tablo 3. Soru 2 için Seçilen Yanıt Kategorilerinin Yüzdesi (Sıklığı): "Bu Uygulama, Bildiğiniz/Çalıştı̆̆ınız Programlar/ Kurumlar Tarafindan Ne Ölçüde Kullanıliyor?”

\begin{tabular}{|c|c|c|c|c|c|}
\hline Konu Alanı & Siklikla & Bazen & Nadiren & Asla & Yanit Yok \\
\hline $\begin{array}{l}\text { Liderlik } \\
\text { (13 uygulama*/3822 yanıt) }\end{array}$ & $\begin{array}{c}1 \\
(38)\end{array}$ & $\begin{array}{c}11 \\
(420)\end{array}$ & $\begin{array}{c}34 \\
(1300)\end{array}$ & $\begin{array}{c}42 \\
(1605)\end{array}$ & $\begin{array}{c}12 \\
(459)\end{array}$ \\
\hline $\begin{array}{l}\text { Değerlendirme } \\
\text { (11 uygulama/3234 yanıt) }\end{array}$ & $\begin{array}{c}6 \\
(194)\end{array}$ & $\begin{array}{c}21 \\
(680)\end{array}$ & $\begin{array}{c}36 \\
(1164)\end{array}$ & $\begin{array}{c}36 \\
(1164)\end{array}$ & $\begin{array}{c}1 \\
(32)\end{array}$ \\
\hline $\begin{array}{l}\text { Çevre } \\
\text { (6 uygulama/1764 yanıt) }\end{array}$ & $\begin{array}{c}1 \\
(18)\end{array}$ & $\begin{array}{c}16 \\
(282)\end{array}$ & $\begin{array}{c}47 \\
(829)\end{array}$ & $\begin{array}{c}32 \\
(564)\end{array}$ & $\begin{array}{c}4 \\
(71)\end{array}$ \\
\hline $\begin{array}{l}\text { Aile } \\
\text { (10 uygulama/2940 yanit) }\end{array}$ & $\begin{array}{c}1 \\
(29)\end{array}$ & $\begin{array}{c}19 \\
(559)\end{array}$ & $\begin{array}{c}52 \\
(1529)\end{array}$ & $\begin{array}{c}22 \\
(647)\end{array}$ & $\begin{array}{c}6 \\
(176)\end{array}$ \\
\hline $\begin{array}{l}\text { Öğretim } \\
\text { (13 uygulama/3822 yanıt) }\end{array}$ & $\begin{array}{c}8 \\
(306)\end{array}$ & $\begin{array}{c}15 \\
(573)\end{array}$ & $\begin{array}{c}37 \\
(1414)\end{array}$ & $\begin{array}{c}39 \\
(1491)\end{array}$ & $\begin{array}{c}1 \\
(38)\end{array}$ \\
\hline $\begin{array}{l}\text { Etkileşim } \\
\text { (5 uygulama/1470 yanıt) }\end{array}$ & $\begin{array}{c}4 \\
(59) \\
\end{array}$ & $\begin{array}{c}17 \\
(250) \\
\end{array}$ & $\begin{array}{c}55 \\
(808) \\
\end{array}$ & $\begin{array}{c}19 \\
(279)\end{array}$ & $\begin{array}{c}5 \\
(74) \\
\end{array}$ \\
\hline $\begin{array}{l}\text { Ekip ve İşbirliği } \\
\text { (5 uygulama/1470 yanıt) }\end{array}$ & $\begin{array}{c}1 \\
(15)\end{array}$ & $\begin{array}{c}20 \\
(294)\end{array}$ & $\begin{array}{c}37 \\
(544)\end{array}$ & $\begin{array}{c}38 \\
(558)\end{array}$ & $\begin{array}{c}4 \\
(59)\end{array}$ \\
\hline $\begin{array}{l}\text { Geçiş } \\
\text { (2 uygulama/588 yanıt) }\end{array}$ & $\begin{array}{c}1 \\
(6)\end{array}$ & $\begin{array}{c}6 \\
(35)\end{array}$ & $\begin{array}{c}31 \\
(182)\end{array}$ & $\begin{array}{c}53 \\
(312)\end{array}$ & $\begin{array}{c}9 \\
(53)\end{array}$ \\
\hline
\end{tabular}

* Liderlik konu alanında 14 uygulama bulunmaktadır; ancak bu konu alanı altında yer alan 11. uygulama Türk eğitim sistemi bağlamında uygulanabilir olmadığı için ankete dahil edilmemiştir.

\section{Paydaş Gruplarının Karşılaştırılması}

Grupların puanlarında bir farklılık olup olmadığını belirlemek amacıyla konu alanlarına göre öğretmenler, veliler, öğretim elemanları veya yöneticilerin ortalama puanları hesaplanmış ve karşılaştırılmıştır. İlk araştırma sorusu için konu alanlarına göre paydaş gruplar arasındaki ANOVA sonuçları Tablo 4'de sunulmuştur. Bu bağlamda Liderlike $(\mathrm{F}[2,291]=22.17)$, Cevre $(\mathrm{F}[2,291]=$ 20.86) ve Aile $(\mathrm{F}[2,291]=8.18)$ konu alanlarında istatistiksel olarak anlamlı bir fark bulunduğu belirlenmiştir. Liderlik konu alanı ile ilişkili yapılan Tukey post-hoc analizi, öğretim elemanları veya yöneticilerinin uygulamaları öğretmenlerden $(\mathrm{p}<.001)$ ve ebeveynlerden $(\mathrm{p}<.001)$ daha olumlu değerlendirdiğini ortaya çıkarmıştır. Benzer şekilde, Çevre konu alanı ile ilişkili yapılan Tukey post- 
hoc analizi, öğretim elemanları veya yöneticilerin uygulamaları, öğretmenlere $(p<.001)$ ve velilere $(\mathrm{p}<.001)$ göre daha olumlu değerlendirdiğini ortaya koymuştur. Aile konu alanı ile ilişkili yapılan post-hoc analizi sonuçları ise öğretmenlerin uygulamaları ebeveynlerden $(p<.001)$ ve öğretim elemanları veya yöneticilerden $(\mathrm{p}<.001)$ daha az olumlu değerlendirdiğini göstermiştir.

Tablo 4. Soru 1 için Konu Alanına Göre Grup Ortalamaları (Standart Sapmaları) ve Gruplar Arasındaki Farklar: "Bu Uygulama, Türkiye'deki EM/EÇÖzE Alanı İçin Tavsiye Edilen Bir Uygulama Olmalı Mıdır?" $(n=294)$

\begin{tabular}{|c|c|c|c|c|c|}
\hline \multirow[b]{2}{*}{ Konu Alanı } & \multicolumn{3}{|c|}{ Ortalama $^{a}(S S)$} & \multicolumn{2}{|c|}{ Tek Yönlü ANOVA } \\
\hline & Öğretmenler & Ebeveynler & $\begin{array}{c}\text { Öğretim Elemanları } \\
\text { veya Yöneticiler }\end{array}$ & $F(2,291)$ & $p$ \\
\hline Liderlik & $1.66(.36)$ & $1.58(.39)$ & $1.32(.25)$ & 22.17 & $<.001 *$ \\
\hline Değerlendirme & $1.30(.34)$ & $1.32(.32)$ & $1.24(.26)$ & 1.42 & .24 \\
\hline Çevre & $1.54(.40)$ & $1.65(.43)$ & $1.25(.39)$ & 20.86 & $<.001 *$ \\
\hline Aile & $1.65(.38)$ & $1.48(.41)$ & $1.45(.35)$ & 8.18 & $<.001 *$ \\
\hline Öğretim & $1.28(.43)$ & $1.20(.25)$ & $1.18(.23)$ & 2.59 & .07 \\
\hline Etkileşim & $1.74(.47)$ & $1.70(.39)$ & $1.58(.45)$ & 3.06 & .05 \\
\hline Ekip ve İşbirliği & $1.66(.34)$ & $1.68(.25)$ & $1.62(.22)$ & 0.95 & .39 \\
\hline Geçiş & $1.47(.44)$ & $1.52(.34)$ & $1.40(.36)$ & 2.00 & .14 \\
\hline
\end{tabular}

Not. SS = Standart sapma; EM = Erken Müdahale; EÇÖzE = Erken Çocuklukta Özel Eğitim.

*Sonuçlar p <.01'de istatistiksel olarak anlamlı kabul edilmiştir.

a 1 = Kesinlikle Katılıyorum, 2 = Kat1liyorum, 3 = Katılmıorum, 4 = Kesinlikle Katılmıyorum

Araştırmanın ikinci sorusu için konu alanlarına göre paydaş grupları arasındaki farkları inceleyen ANOVA sonuçlar1 Tablo 5'te sunulmuştur. Değerlendirme $(\mathrm{F}[2,291]=14.26)$ ve Aile $(\mathrm{F}[2,291]=$ 16.05) konu alanlarında gruplar arasında istatistiksel olarak anlamlı bir fark gözlemlenmiştir. Her iki konu alanı için de ebeveynlerin puanlarının öğretmenlerden $(\mathrm{p}<.001)$ ve öğretim elemanları veya yöneticilerden $(\mathrm{p}<.001)$ daha yüksek olduğu belirlenmiştir.

Tablo 5. Soru 2 için Konu Alanına Göre Grup Ortalamaları (Standart Sapmaları) ve Gruplar Arasındaki Farklar: "Bu Uygulama, Bildiğiniz/Çalıştı̆̆ınız Programlar/ Kurumlar Tarafından Ne Ölçüde Kullanılıyor?” $(n=294)$

\begin{tabular}{lccccc}
\hline \multicolumn{1}{c}{ Konu Alanı } & \multicolumn{2}{c}{ Ortalama $^{a}(S S)$} & \multicolumn{2}{c}{ Tek Yönlü ANOVA } \\
\hline Liderlik & $2.98(.45)$ & $2.93(.42)$ & $2.88(.44)$ & 1.20 & .30 \\
\hline Değerlendirme & $2.94(.46)$ & $3.20(.37)$ & $2.86(.54)$ & 14.26 & $<.001^{*}$ \\
\hline Çevre & $3.02(.47)$ & $3.08(.43)$ & $2.96(.39)$ & 1.60 & .20 \\
\hline Aile & $2.64(.65)$ & $3.06(.44)$ & $2.80(.51)$ & 16.05 & $<.001^{*}$ \\
\hline Öğretim & $3.00(.51)$ & $3.11(.44)$ & $3.04(.56)$ & 1.34 & .26 \\
\hline
\end{tabular}




\begin{tabular}{llllll}
\hline Etkileşim & $2.75(.55)$ & $2.70(.63)$ & $2.92(.48)$ & 3.40 & .04 \\
\hline Ekip ve İşbirliği & $2.98(.44)$ & $3.06(.51)$ & $3.08(.65)$ & 1.05 & .35 \\
\hline Geçiş & $3.13(.35)$ & $3.21(.30)$ & $3.22(.42)$ & 1.83 & .16 \\
\hline
\end{tabular}

Not. SS = Standart Sapma.

*Sonuçlar $\mathrm{p}<.01$ 'de istatistiksel olarak anlamlı kabul edilmiștir.

a 1 = S1klıkla, 2 = Bazen, $3=$ Nadiren, $4=$ Asla

\section{SONUÇ ve TARTIŞMA}

Bu çalışma, Özel Gereksinimli Çocuklar Konseyi (CEC) Erken Çocukluk Birimi (DEC) tarafindan yeni belirlenen tavsiye edilen uygulamaların uluslararası bağlamda geçerliliğinin belirlenmesini amaçlamıştır. Bu bağlamda, Türkiye'deki EM/EÇÖzE alanı paydaşlarına, Erken Çocukluk Birimi tarafından yeni belirlenen tavsiye edilen uygulamaların ülkemiz EM/EÇÖzE alanı için tavsiye edilen uygulamalar olarak kabul edilip edilemeyeceği ve bu uygulamaların programlar ve kurumlar kapsamında ne ölçüde kullanıldığ1 sorulmuştur. Bulgular, 65 uygulamanın hepsinin geçerlilik ölçütünü karşıladığını (katılımcıların \%50'den fazlası her bir uygulama için "katıllyorum veya kesinlikle katıllyorum" seçeneklerini işaretlemiştir) ve tüm TEdU'ların Türkiye'deki paydaşlar tarafından önemli olarak algılandığını göstermiştir. Bu umut verici bulguların aksine kullanıma ilişkin bulgular, TEdU'ların erken eğitim ortamlarında EM/EÇÖzE uzmanları tarafından nadiren kullanıldığını veya hiç kullanılmadığını göstermiştir.

Tablo 2'de görüldüğü gibi katılımcılar tarafından her konu alanında en sık verilen cevap "kesinlikle katılıyorum veya katılıyorum” şeklindedir. Bu bulgular umut verici olmakla birlikte katılımcıların Ekip ve $\dot{I}_{s}$ birliğ (\%10), Etkileşim (\%10) ve Aile (\%9) gibi konu alanlarında nispeten yüksek düzeyde "katılmıyorum veya kesinlikle katılmıyorum" seçeneklerini işaretlemeleri, bu alanlardaki uygulamalar için daha az destek verildiğini göstermektedir. Ülkemizde, gelişimsel yetersizliğe sahip olan veya risk altında olan küçük çocuklar için sağlanan eğitim programları ve hizmetleri genellikle bir yetişkin (çoğu zaman bir özel eğitim öğretmeni) tarafından sunulmakta ve EM/EÇÖzE hizmetlerinin sunulmasında birden fazla uzmanın yer alması durumunda ise çok az etkileşimli multidisipliner ekip modeli benimsenmektedir. Multidisipliner ekip yaklaşımının kullanıldığı durumlarda ebeveynler farklı meslek uzmanları arasındaki etkileşimi kolaylaştırma rolünü üstlenmek zorunda kalabilmektedir. Aile merkezli uygumalar bağlamında, Türkiye'deki EM/EÇÖzE hizmetlerinin hala uzman merkezli olduğu görülmektedir. Bu nedenle, çoğu durumda, ebeveynler çocuklarıyla ilgili karar verme sürecine en alt düzeyde dahil olmakta (genellikle sadece uzmanlar tarafından hazırlanan evrakları imzalamaya dahil olurlar) ve mevcut EM/EÇÖzE sistemi içerisinde ailelerin gereksinimlerini karşılayacak destekler bulunmamaktadır. Dahası, üç yaşından 
küçük, yetersizliği olan çocuklar için devlet tarafından finanse edilen resmi bir erken müdahale sistemi ya da hizmeti bulunmamaktadır.

Tablo 2'de dikkat çeken bir diğer bulgu da Liderlik (\%12) ve Geçiş (\%9) konu alanları için nispeten yüksek seviyede "kararsızım" seçeneğinin işaretlenmiş olmasıdır. Bu iki konu alanı, Türkiye'de EM/EÇÖzE alanında nispeten yeni tartışılan konu alanlarıdır. Bu nedenle, bu konu alanları altında yer alan bazı uygulamalar paydaş gruplar tarafından iyi anlaşılamamış olabilir. Uygulayıcıların (örn., özel eğitim ya da okulöncesi öğretmeni veya terapistler), EM/EÇÖzE uygulamalarının yetersizlikten etkilenmiş küçük çocuklar ve aileleri için olumlu sonuçlar ortaya çıarması bağlamındaki rolleri oldukça önemlidir. Ancak, uygulayıcıların, bu hedef gruplarla çalışırken tavsiye edilen uygulamaları uygulamak için çalıştıkları okullardan, kurumlardan ya da Bakanlıktan destek almaları gerekmektedir. Türkiye'deki özel eğitim yasaları ve yönetmelikleri EM/EÇÖzE hizmetlerinin nasıl tasarlanması, geliştirilmesi ve uygulanması gerektiği konusunda sınırlı düzeyde bilgiler içermekte ve bu süreçte yöneticiler ile diğer liderlerin rolleri hakkında bir rehberlik sağlamamaktadır. Bu nedenle, uygulayıcılar hizmetleri planlama ve uygulama sırasında karşılaşılan birçok soruna kendi kendilerine çözüm bulmaya çalışmaktadırlar. Dahası, yakın zamana kadar geçişler, EM/EÇÖzE kapsamında bir sorun ya da öncelik olarak görülmemekteydi. Bunun başlıca nedeni yetersizliği olan küçük çocuklara özellikle 0-3 yaş arasında sunulan EM hizmetlerinin sınırlı olmasıdır. Doğumdan beş yaşına kadar olan çocuklara sunulan EM/EÇÖzE hizmetlerin geliştirilip yaygınlaştırılması ve 0-3 yaş grubundaki çocuklar ve ailelerine sunulacak hizmetlerin daha sık tartışılması ile birlikte, geçişlerin planlanması önemli hale gelecek ve bu alandaki uygulamaların değeri daha iyi anlaşılacaktır.

Tablo 3'de görüldüğ̈ gibi konu alanına göre TEdU’ların mevcut kullanımı ile ilgili soru bağlamında katılımcıların en sık kullandıkları yanıtlar "nadiren veya asla" seçenekleridir. Dahası, hiçbir konu alanı için "sıklıkla ve bazen” derecelendirmelerinin toplamı \%50'yi geçmemiştir. Katılımcılar, Geçis (\%7) ve Liderlik (\%12) ile ilgili uygulamaların en az uygulandığını, Değerlendirme (\%27) ve Ögrretim (\%23) ile ilgili uygulamaların ise en fazla uygulanıldığını rapor etmişlerdir. Sonuç olarak, TEdU'ların rapor edilen uygulama düzeyinin istenen uygulama seviyelerinin çok altında olduğu görülmektedir.

İlk araştırma sorusu için paydaş gruplar arasındaki karşılaştırma üç konu alanında (Liderlike, Çevre ve Aile) istatistiksel olarak anlamlı bir farklılık ortaya koymuştur (Tablo 4). Bu bağlamda, yükseköğretim kurumlarında çalışan öğretim elemanları ile yöneticilerin tüm konu alanlarındaki ortalama puanlarının öğretmenler ve ebeveynlerden daha yüksek olduğunu görülmektedir. Bu bulgu, McLean vd. (2002) tarafindan rapor edilen, diğer paydaş gruplarına kıyasla, tüm konu 
alanlarında öğretim elemanları ile yöneticilerin daha yüksek ortalama puana sahip olduklarına yönelik bulgularla tutarlılık göstermektedir. Ayrıca, ebeveynlerin dört konu alanında (Liderlik, Aile, Ögretim ve Etkileşim) öğretmenlerden daha yüksek ortalama puanlara sahip olduğu ve öğretmenlerin de kalan dört konu alanında ebeveynlerden daha yüksek ortalama puanlara sahip olduğu görülmüştür. Ancak, ebeveynlerin ve öğretmenlerin ortalama puanları arasında istatistiksel olarak anlamlı tek fark Aile konu alanında gözlenmiştir. Diğer konu alanlarındaki ortalama farkları istatistiksel olarak anlamlı şekilde farklı bulunmamıştır.

Tablo 5'te sunulduğu gibi ikinci soru bağlamında iki konu alanında (Değerlendirme ve Aile) paydaş gruplarının puanları arasında istatistiksel olarak anlamlı farklılıklara rastlanmıştır. Yükseköğretim kurumlarında görev yapan öğretim elemanları ile yöneticiler, dört konu alanında (Liderlik, Değerlendirme, Çevre ve Öğretim) yer alan ilişkili uygulamaların öğretmenlere veya ebeveynlere kiyasla daha sık uygulandığını rapor etmişlerdir. Öğretmenler, üç konu alanında (Aile, Ekip ve İşbirliği, Geçiş) ilişkili uygulamaların kullanımını diğer gruplardan daha sık gözlemlediklerini bildirmişlerdir ve ebeveynler de bir konu alanında (Etkileşim) ilişkili uygulamalanı diğer uygulamalardan daha sık uyguladıklarını belirtmişlerdir. McLean vd. (2002) yaptıkları araştırmada, uygulayıcılar dört konu alanı ile (Değerlendirme, Çocuk Odaklı Müdahaleler, Aile Temelli Uygulamalar ve Disiplinlerarası Modeller) ilişkili uygulamaların daha sık uygulandığını; öğretim elemanları veya yöneticiler bir konu alanı altındaki (Personel Hazırlığı) uygulamaların daha sık kullanıldığını belirtmiştir. İki konu alanı altında (Teknoloji Uygulamaları ve Politika ve Sistem Değişikliği) yer alan uygulamaların kullanım sıklı̆̆1 konusunda uygulayıcılar ve öğretim elemanları veya yöneticiler benzer görüşler belirtmişlerdir. Tüm konu alanları için, ebeveynler, ilişkili uygulamaların kullanımını en az sıklıkla gözlemleyen katılımcı grubu olmuşlardır. Bu bağlamda, ebeveynlere ilişkin bulguların ABD ve Türkiye'de benzerlik gösterdiği görülmektedir.

Genel olarak bu çalısmanın bulguları, paydaşların çoğunluğunun Özel Gereksinimli Çocuklar Konseyi Erken Çocukluk Birimi tarafından geliştirilen TEdU’ların Türkiye'de EM/EÇÖzE alanı için tavsiye edilen uygulamalar olarak kabul edilmesini onayladığını gösterirken, öğretmenlerin ve diğer uygulayıcıların bu uygulamaları yetersizlikten etkilenmiş küçük çocuklarla ve aileleriyle çalışırken nadiren kullandığını ortaya koymuştur. Bu iki bulgu birlikte, öğretmenlerin ve diğer EM/EÇÖzE hizmet sağlayıcılarının uygulamalarında TEdU'ları kullanmasını kolaylaştırmak için sistem düzeyinde bir destek ve altyapı geliştirilmesine olan ihtiyacı ortaya koymaktadır. 


\section{Gelecekteki Uygulamalar için Öneriler}

Farklı paydaşların TEdU'ları onaylamaları ve TEdU'ların uygulayıcılar tarafindan nadiren kullanıldığı göz önüne alındığında, TEdU’ların uygulayıcılar tarafından kullanımını teşvik etmek için çeşitli adımlar atılması gerekmektedir. İlk olarak, TEdU'lar EM/EÇÖzE uygulayıcılarını yetiştiren lisans veya yüksek lisans programlarında (örn., özel eğitim öğretmenliği, okulöncesi öğretmenliği, çocuk gelişimi ve dil-konuşma terapisi) sunulan derslere entegre edilmelidir. Türkiye'de EM/EÇÖzE alanında hizmet sunun uygulamacıları eğitmek için özel bir lisans ya da yüksek lisans programı olmamasına karşın özel eğitim ve okulöncesi öğretmenliği programları mezunları yetersizlikten etkilenmiş küçük çocuklara hizmet vermektedir. Bu programların müfredatlarında, yetersizlikten etkilenmiş küçük çocukların eğitimi ve bu çocukların aileleriyle çalışma konularını içeren dersler yer almaktadır. TEdU'lardan bazıları halihazırda bu dersler kapsamında tanımlanmakta ve ele alınmaktadır. Bununla birlikte, uygulamada yaygın kullanımı teşvik etmek ve yetersizlikten etkilenmiş küçük çocuklara ve ailelerine sunulan hizmetlerin kalitesini artırmak için TEdU'ların planlı olarak öğretilmesi gerekmektedir.

Türkiye'de TEdU'ların kullanımını teşvik etmek için atılabilecek ikinci adım ise bu uygulamaların alanda yetersizlikten etkilenmiş çocuklarla ve aileleriyle çalışan uygulayıcılar için tasarlanmış mesleki gelişim faaliyetleri kapsamında ayrıntılı olarak ele alınmasıdır. Bu amaçla, Erken Çocukluk Teknik Yardım Merkezi'nin çalışmalarına benzer şekilde, her konu alanı için web tabanlı mesleki gelişim modülleri ve materyalleri geliştirilerek TEdU'lar tüm uygulayıcılar için erişilebilir hale getirilmelidir. Web tabanlı platformlar, hizmet sağlayıcılarının herhangi bir yer ve zamanda ya da gereksinim duyduklarında bilgi ve dokümanlara kolaylıkla erişmelerine olanak tanıyacaktadır.

Türkiye'deki özel eğitim yasaları ve yönetmelikleri, tavsiye edilen uygulamaların birçoğunun uygulanması için gerekli temele sahiptir. Örneğin, 573 sayılı Kanun Hükmünde Kararname'nin Madde 11'inde "0-36 aylık özel eğitim ihtiyacı olan çocuklar için erken çocukluk dönemi hizmetleri, ailenin bilgilendirilmesini ve desteklenmesini de içerecek şekilde yürütülür.” ifadesi yer almaktadır. (Diken vd., 2016). Kararnamenin 11. maddesi, farklı konu alanları altında (örn., Çevre, Aile, Öğretim) birçok TEdU'nun uygulanmasına zemin oluşturmaktadır. Bununla birlikte, mevzuatlara dayanarak ne yapılacağına karar vermek genellikle yöneticilerin veya uygulayıcıların inisiyatifindedir ve bu uygulayıcıların EM/EÇÖzE uygulamaları sırasında ne yapacakları TEdU veya genel olarak herhangi bir uygulama hakkında bildikleriyle yakından ilişkilidir. Bu nedenle, tavsiye edilen uygulamalar ve bunların nasıl uygulanacağı hakkında daha fazla bilgi edinmek, mevzuatların daha iyi yorumlanmasını kolaylaştırabilir ve sonuç olarak, EM/EÇÖzE hizmetlerinin yetersizlikten 
etkilenmiş küçük çocuklar ve aileleri için daha olumlu sonuçlar ortaya çıkarmasına katkıda bulunabilir.

\section{Sinirlılıklar}

Bu çalışmanın, sonuçları yorumlanırken dikkate alınması gereken en az iki sınırlılı̆̆ı bulunmaktadır. Birincisi, çalışma kapsamında toplanan veriler sadece yedi şehirden toplanmıştır. Araştırmanın Türkiye'nin yedi bölgesini de temsil edecek şekilde daha geniş bir örneklemle gerçekleştirilmesi, bu araştırmada ele alınan konunun kapsamlı bir şekilde tartışılmasına hizmet edecektir. İkincisi, bu araştırma kapsamında toplanan, TEdU'ların uygulanma sıklığına yönelik veriler yalnızca katılımcı raporuna dayanmaktadır. EM/EÇÖzE uygulamaları sırasında TEdU'ların uygulanma düzeyinin gözleme dayalı veriler ile desteklenmesi araştırma bulguların daha güvenilir hale gelmesini sağlayacaktır. Bu sınırlılıkların gelecekte bu araştırmanın konu alanıyla ilgili başka araştırmalara yön verecek nitelikte olduğu düşünülmektedir.

\section{Sonuç}

1990’lı yıllarda Amerika Birleşik Devletleri’nde yeni gelişmekte olan EM/EÇÖzE alanına rehberlik etmesi amacıyla Özel Gereksinimli Çocuklar Konseyi Erken Çocukluk Birimi tarafından geliştirilen ve ylllar içerisinde birkaç farklı revizyondan geçen TEdU, Türkiye'de yaygınlaşmakta olan EM/EÇÖzE alanına ve bu bağlamda sunulan hizmetlere yön verebilecek ve destek olabilecek niteliktedir. Bu çalışmaya katılan EM/EÇÖzE paydaşları, TEdU’ların tamamının önemli uygulamalar içerdiğini onaylamış ve alanda nadiren kullanıldıklarını belirtmişlerdir. Bu çalışmanın bulguları doğrultusunda, TEdU'ların Türkiye'deki EM/EÇÖzE hizmetleri bağlamında yaygın bir şekilde kullanılmasını desteklemek amacıyla çeşitli sistemsel değişikliklerin ve yasal düzenlemelerin yapılması önerilmektedir.

\section{KAYNAKÇA}

Büyüköztürk, Ş., Çakmak, E. K., Akgün, Ö. E., Karadeniz, Ş. ve Demirel, F. (2019). Bilimsel araștırma yöntemleri (27. Baski). Ankara: Pegem Akademi.

Diken, I. H., Rakap, S., Diken, O., Tomris, G., \& Celik, S. (2016). Early childhood inclusion in Turkey. Infants \& Young Children, 29(3), 231-238.

Division for Early Childhood. (2014). DEC recommended practices in early intervention/ early childhood special education 2014. Los Angeles, CA: Author.

Division of Early Childhood. (2000). Personnel standards for early education and early intervention: Guidelines for licensure in early childhood special education. Missoula, MT: Author. 
McLean, M. E., Snyder, P., Smith, B. J., \& Sandall, S. R. (2002). The DEC recommended practices in early intervention/early childhood special education: Social validation. Journal of Early Intervention, 25(2), 120-128.

McLean, M., Swett, J \& Trivette, C. (May, 2014). DEC recommended practices: How do we ensure application and use? Chapel Hill, NC: National Early Childhood Inclusion Institute.

Odom, S. L., \& McLean, M. E. (1996). Early intervention/early childhood special education recommended practices. Austin, TX: PRO-ED, Inc.

Odom, S., McLean, M., Johnson, L., \& LaMontaigne, M. (1995). Recommended practices in early intervention/early childhood special education. Journal of Early Intervention, 19(1), 1-17.

Rakap, S. (Ed.). (2017). Türkiye'de Otizm Spektrum Bozukluğu ve Özel Ĕ̈itim [Autism spectrum disorder and special education in Turkey]. Istanbul: Tohum Autism Foundation.

Rakap, S., \& Rakap, S. (2015, October). Cross-cultural validation of DEC Recommended Practices: Key stakeholders' opinions from Turkey. Poster presented at the $31^{\text {th }}$ International Division for Early Childhood Conference, Atlanta, GA.

Rapport, M. J. K., McWilliam, R. A., \& Smith, B. J. (2004). Practices across disciplines in early intervention: The research base. Infants \& Young Children, 17(1), 32-44.

Sandall, S., Hemmeter, M. L., Smith, B. J., \& McLean, M. E. (2005). DEC recommended practices in early intervention/ early childhood special education: A comprehensive guide. Missoula, MT: Division for Early Childhood. 